\title{
Trapping for invasive crayfish: comparisons of efficacy and selectivity of baited traps versus novel artificial refuge traps
}

\author{
Nicky Green ${ }^{1}$, Matt Bentley ${ }^{1,2}$, Paul Stebbing ${ }^{3}$, Demetra Andreou ${ }^{1}$ and Robert Britton ${ }^{1, *}$ \\ ${ }^{1}$ Department of Life and Environmental Sciences, Faculty of Science and Technology, Bournemouth University, Poole, BH12 5BB, UK \\ ${ }^{2}$ Newcastle University in Singapore, SIT @NYP Building, 172A Ang Mo Kio Avenue 8, \#05-01, Singapore, Singapore \\ ${ }^{3}$ Centre for Environment, Fisheries and Aquaculture Science (CEFAS), The Nothe, Barrack Road, Weymouth, Dorset DT4 8UB, UK
}

\begin{abstract}
Non-native crayfish can dominate the invertebrate biomass of invaded freshwaters, with their high ecological impacts resulting in their populations being controlled by numerous methods, especially trapping. Although baited funnel traps (BTs) are commonly used, they tend to be selective in mainly catching largebodied males. Here, the efficacy and selectivity of BTs were tested against an alternative trapping method based on artificial refuges (ARTs) that comprised of a metal base with several tubes (refuges) attached. The target species was signal crayfish Pacifastacus leniusculus in an upland river in southwest England. Trapping was completed in April to October over two consecutive years. In total, 5897 crayfish were captured, with 87\% captured in ARTs. Comparison of the catch per unit effort (CPUE) between the trapping methods in the same 24 hour periods revealed significantly higher CPUE in ARTs than of BTs. ARTs fished for 6 consecutive days had higher catches than both methods over 24 hours. Whilst catches in BTs were significantly dominated by males (1.49M:1F), the sex ratio of catches in ARTs was $0.99 \mathrm{M}: 1 \mathrm{~F}$. The mean carapace length of crayfish was also significantly larger in BTs $(43.2 \pm 0.6 \mathrm{~mm})$ than in ARTs $(33.6 \pm 0.2 \mathrm{~mm})$. Thus, ARTs had higher CPUE over 24 hour and 6 day periods versus BTs and also captured a greater proportion of smaller and female individuals. These results indicate that when trapping methods are deployed for managing invasions, the use of ARTs removes substantial numbers of crayfish of both sexes and of varying body sizes.
\end{abstract}

Keywords: Alien species / introduction / invasion management / crayfish trap / Pacifastacus leniusculus

Résumé - Piégeage des écrevisses invasives: comparaisons de l'efficacité et de la sélectivité des pièges appâtés par rapport aux nouveaux pièges refuges artificiels. Les écrevisses non indigènes peuvent dominer la biomasse d'invertébrés des eaux douces envahies, et leur impacts écologiques élevés ont pour conséquence que leurs populations sont contrôlées par de nombreuses méthodes, en particulier le piégeage. Bien que les pièges à entonnoir appâtés (BT) soient couramment utilisés, ils ont tendance à être sélectifs surtout chez les mâles de grande taille. Ici, l'efficacité et la sélectivité des BTont été testées par rapport à une méthode alternative de piégeage basée sur des refuges artificiels (ARTs) composés d'une base métallique avec plusieurs tubes (refuges) attachés. L'espèce cible était l'écrevisse signal Pacifastacus leniusculus dans une rivière des hautes terres du sud-ouest de l'Angleterre. Le piégeage s'est déroulé d'avril à octobre sur deux années consécutives. Au total, 5,897 écrevisses ont été capturées, dont 87\% dans des ART. La comparaison des CPUE entre les méthodes de piégeage dans les mêmes périodes de 24 heures a révélé des CPUE significativement plus élevées dans les ART que dans les BT. Les ART posés pendant 6 jours consécutifs ont donné des prises plus élevées que les deux méthodes sur 24 heures. Alors que les prises dans les BT étaient significativement dominées par les mâles (1,49M: 1F), le sex-ratio des prises dans les ART était de 0,99M: 1F. La longueur moyenne de la carapace des écrevisses était également significativement plus grande chez les BT $(43,2 \pm 0,6$ $\mathrm{mm})$ que chez les ART (33,6 $\pm 0,2 \mathrm{~mm})$. Ainsi, les ART avaient une CPUE plus élevée sur des périodes de 24 heures et de 6 jours par rapport aux BT et capturaient également une plus grande proportion d'individus plus petits et femelles. Ces résultats indiquent que lorsque des méthodes de piégeage sont utilisées pour gérer les invasions, l'utilisation des ART élimine un nombre important d'écrevisses des deux sexes et de tailles variables.

Mots clés : Espèces exotiques / introduction / gestion des invasions / piège à écrevisses / Pacifastacus leniusculus

\footnotetext{
*Corresponding author: rbritton@bournemouth.ac.uk
} 


\section{Introduction}

Biological invasions are a major threat to native biodiversity and result in biotic homogenisation at global scales (Arim et al., 2006; Andreou et al., 2011). Non-native crayfish are very successful invaders, with some species having achieved distributions across a number of continents (Capinha et al., 2011). These crayfish frequently dominate the invertebrate biomass of freshwater ecosystems, substantially altering native communities and ecosystem functioning (Lodge et al., 2012; Twardochleb et al., 2013; Jackson et al., 2016). Whilst many of their impacts result from trophic interactions with native species (Jackson et al., 2014), they also impact native crayfish through displacement and pathogen transfer (Holdich and Reeve, 1991; Lodge et al., 2012). Their introduction into Great Britain occurred via aquaculture in the 1970s with the introduction of the American signal crayfish Pacifastacus leniusculus and has resulted in multiple ecological impacts (e.g. Holdich et al., 2014; Mathers et al., 2016), including populations declines in native white-clawed crayfish Austropotamobius pallipes and increased riverine sediment deposition rates (Holdich et al., 2014; Rice et al., 2014; Mathers et al., 2016).

Given the wide-ranging ecological impacts of invasive crayfish, their populations have been subjected to numerous methods for control, containment and eradication. These approaches have included mechanical and physical removal, biological control and biocide application, with autocidal methods also proposed (cf. Gherardi et al., 2011; Stebbing et al., 2014). Despite management efforts, most mitigation and remediation options remain under-explored (Gherardi et al., 2011). Where control methods have been applied over extended time periods then substantial reductions in population abundances (but not extirpation) have been recorded, with concomitant recovery in aspects of the impacted native biota (Hein et al., 2007; Dana et al., 2010), or it has facilitated their co-existence with native taxa (Kats et al., 2013). A major issue with the application of these management methods is, however, that they require substantial effort and commitment, coupled with the catch composition of many methods, especially trapping and removal, being size- and/or sexbiased, resulting in only a proportion of the population being targeted and removed, with a typical bias towards larger individuals (e.g. Freeman et al., 2010; Stebbing et al., 2014). In addition, as the crayfish density reduces through removals then the remaining individuals become harder to catch, as many removal methods are ineffective on low-density populations (Stebbing et al., 2014).

For population control programmes to be successful, Bomford and O'Brien (1995) suggested a number of criteria have to be met, including that all reproductive animals must be at risk of capture, with their capture still probable at low population density. For invasive crayfish, an issue is the low rates of capture and removal of juveniles $(<30 \mathrm{~mm}$ carapace length), despite them often comprising a high proportion of population abundance (Houghton et al., 2017). Thus, trapping methods that are biased towards the capture of only mature crayfish tend to result in poor control efficiency due to much of the population remaining unaffected (Peay, 2004). The sizeselectivity of trapping tends to be most apparent when conventional funnel or baited traps are used, with large adults, particularly males, most frequently captured (Freeman et al., 2010; Gherardi et al., 2011). Baited traps are also relatively labour intensive with, for example, them having to be emptied every 24 hours in the UK due to legislative requirements; they are also more suitable for lentic or deep, slow moving lotic waters. They can also capture non-target species such as water vole Arvicola amphibious, whilst smaller crayfish readily escape (Kozak and Policar, 2002). Nevertheless, their use remains commonplace owing to, for example, their availability and known efficacy that enable comparison with data from other studies (Larson and Olden, 2016). Given the issues highlighted with baited traps there remains an outstanding need for a more effective and less selective trapping method for monitoring and/or controlling invasive crayfish populations, with such non-size selective methods then also serving to provide strong data on their populations.

Given these biases of funnel traps, alternative traps have been developed in order to target smaller crayfish, including microhabitat traps (Parkyn et al., 2011), enclosure traps (Engdahl et al., 2013) and nest traps made from plastic pipe (Bechler et al., 2014). Whilst results suggest improved juvenile capture, these designs have not yet been adopted widely or cited as a potential control method. An alternative is the Artificial Refuge Trap (ART), a series of plastic tubes that mimic natural refugia, such as burrows and crevices beneath stones (Peay, 2004). Crayfish will readily utilise ARTs as shelter during inactive periods in the same way they use natural refugia. As they are also not considered a trap until lifted then they are not necessarily subject to animal welfare legislation (in the UK at least) and can be left in situ over extended periods without regular checks. Initial pilot trials suggested ARTs are more efficient than both baited traps and manual searches at detecting low-density crayfish populations in lotic systems, with catches being unbiased or female-biased regarding sex, with capture of a wider size range (Scott, 2012; Walter, 2012). Their use has, however, yet to be tested fully versus other trapping methods.

The aim of this study was, therefore, to quantify the ART efficiency versus the most commonly used trap in Europe, the funnel or baited trap (BT) through comparison of catch rates, composition of the catch and the time taken to deploy each type of trap. Given the pilot studies outlined above, it was hypothesised that compared with BTs, ARTs will capture more representative size ranges and sex ratios of invasive crayfish.

\section{Methods}

\subsection{Study site and trapping periods}

The trapping and removal of $P$. leniusculus using standard BTs and ARTs took place over two trapping periods, in 2015 and 2016. Trapping during winter periods was not possible due to elevated flow rates at the study site, coupled with crayfish being relatively inactive in winter and thus harder to capture. The trapping site was a $1250 \mathrm{~m}$ stretch of the River Barle at Withypool, Exmoor, south-west England $\left(51^{\circ} 06^{\prime} 24.2^{\prime \prime} \mathrm{N}\right.$; $\left.3^{\circ} 39^{\prime} 32.2^{\prime \prime} \mathrm{W}\right)$. This river is a typical upland river, having relatively low productivity and variable flows $\left(\mathrm{Q}_{95}\right.$ : $0.63 \mathrm{~m}^{3} \cdot \mathrm{s}^{-1} ; \mathrm{Q}_{50}: 3.32 \mathrm{~m}^{3} \cdot \mathrm{s}^{-1} ; \mathrm{Q}_{10}: 11.50 \mathrm{~m}^{3} \cdot \mathrm{s}^{-1} ; \mathrm{CEH}$, 2017). In the study area, average widths were between 8 to $10 \mathrm{~m}$ and depths were generally 0.3 to $0.7 \mathrm{~m}$. Substratum 


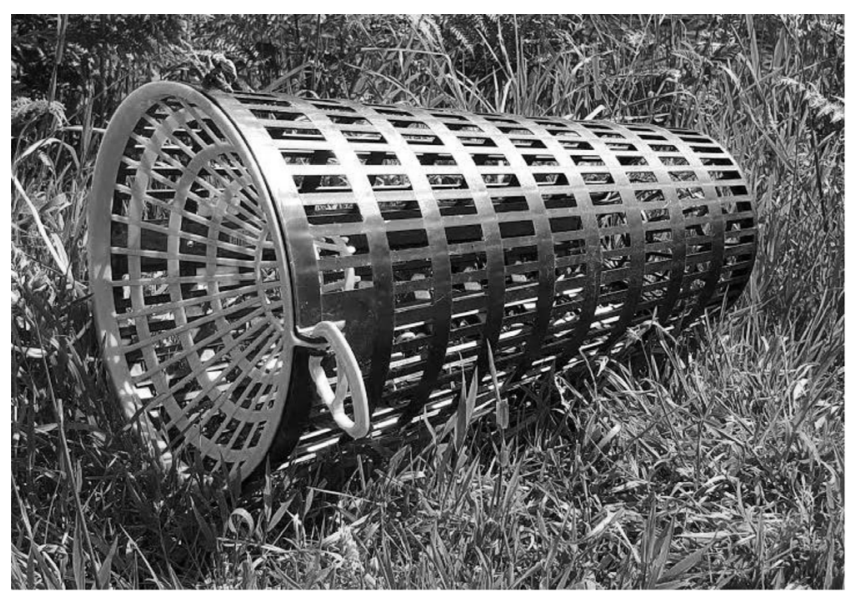

(A)

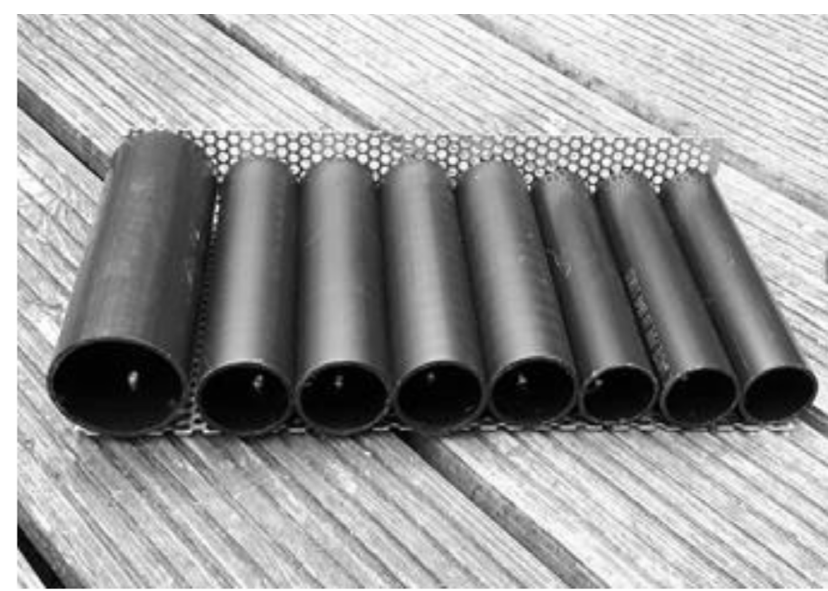

(B)

Fig. 1. The design of the (A) Baited trap; and (B) Artificial refuge trap.

consisted predominantly of a mix of bedrock, boulder and large cobble, with small cobble, gravel and sand/silt towards the banks. The riparian zone was a mix of trees, grassland/ scrub and exposed earth, being subject to extensive burrowing by the crayfish. The river has Site of Special Scientific Interest (SSSI) designation for features including its population of Atlantic salmon Salmo salar (Natural England, 2017). The P. leniusculus population is well established over a $10 \mathrm{~km}$ stretch of the river, with the stretch of river utilised near to the approximate middle of their current distribution.

\subsection{Trap designs}

The artificial refuge trap (ART), also known as the Hutchins trap, pan-pipe trap or multiple tube trap, consists of a series of tubes of 32 to $55 \mathrm{~mm}$ diameter and 150 to $250 \mathrm{~mm}$ long that are attached to a metal baseplate. The ARTs used in the study comprised of either 7 or 8 tubes of lengths 150 to $170 \mathrm{~mm}$ that were attached to a $2 \mathrm{~mm}$ thick perforated aluminium base of 300 to $330 \mathrm{~mm}$ long (Fig. 1). The tube sizes were a mix of 32,40 , and 50 to $55 \mathrm{~mm}$ diameters, with the most frequent $(70 \%$ of all traps) combinations being $3 \times 32,3 \times 40$ and $1 \times 50 \mathrm{~mm}$, all $170 \mathrm{~mm}$ long. A total of 125 ARTs were deployed at $10 \mathrm{~m}$ intervals along the $1250 \mathrm{~m}$ study site. The baited traps (or Swedish 'Trappy' Traps) were typically a cylindrical structure constructed of plastic mesh. The BTs (Fig. 1) were the Trappy $\mathrm{XL}^{\mathrm{TM}}$ type, with entrances at both ends and dimensions $500 \times 280 \mathrm{~mm}$, tapering to $180 \mathrm{~mm}$, with diamond shaped mesh of size of $30 \times 20 \mathrm{~mm}$ (Trappy, 2017). All trapping was carried out under licence consented by the Environment Agency. The BTs were baited with either cat food or sardines in oil, with their application to specific traps being selected randomly.

\subsection{Trapping methodology and crayfish collection and movement}

Deployment of both traps was conducted between 05/05/ 2015 and 27/10/2015, and 12/04/2016 and 19/10/2016. During both trapping periods, traps were deployed every $10 \mathrm{~m}$ along the study reach. At each of these trapping sites, one ART (weighed down by river substratum) and one BT were deployed (between 0.3 and $3.0 \mathrm{~m}$ apart, with the distance dependent on water depth). Both trap types were tied to a wooden stake in the riparian zone. The only exception was that under very low and high flows, BTs could not be deployed at every location due to being exposed (low flow) or displaced (high flow). Whilst ARTs were occasionally washed out during very high flows or dried out when flows were reduced, crayfish were sometimes caught under such conditions, so the total number of 125 ARTs was maintained throughout subsequent data analyses, except when the trap was washed out of the river completely.

The ARTs were left in situ throughout both trapping periods, with a brief period of removal each week when the crayfish that had colonised the pipes were removed. In contrast, each BT was deployed once per week, with fishing over a 24-hour period due to extant legislative requirements. When each BT was deployed, the ART was emptied and reset, and when the BT was lifted the following day, the ART was emptied a second time (24-hour soak) and then redeployed (resulting in a 6-day soak to the next trapping day). Due to variability in flows, the day of lifting the ARTs and setting the BTs for their 24-hour soak varied; whilst it was scheduled for every 7 days, occasionally a week had to be missed due to very high flows, resulting in an occasional 7 or 13-day soak for the ARTs. Data from these 7 or 13-day ART soaks were not included in subsequent data analyses. Consequently, this resulted in a total of 39 trap days over 21 weeks in 2015 and 49 trap days over 27 weeks in 2016 . The data from these trapping days were thus the number of crayfish captured per trap over the 24-hour trapping period (BT and ART), and the number of crayfish captured over the 6-day interim period (ART only).

On their removal from the traps, the captured crayfish were counted and held in water-filled containers during processing. For each individual crayfish, its sex and carapace length (CL; nearest $\mathrm{mm}$ ) were recorded, along with their reproductive state, moult status and any signs of damage or disease. Sex was recorded as male, female or indeterminate for those $<12 \mathrm{~mm}$ CL (where sex could not be determined). In addition, the crayfish were also categorised as small $(<21 \mathrm{~mm} \mathrm{CL}$; likely to 
be young-of-the-year), medium ( 21 to $39 \mathrm{~mm} \mathrm{CL}$; likely to be sub-adults and subordinate adults including breeding females), and large ( $\geq 40 \mathrm{~mm}$ CL; likely to be adults and berried females) (Stebbing et al., 2012). Captured crayfish were not returned to the river due to their non-native status, with individuals euthanized by a cut to the carapace. The exception was for some large males that were returned (under licence) to enable a separate experiment to be completed on male sterilisation. Subsequent recaptures of these males (as identified by their sterilisation) were excluded from the dataset. During some sampling occasions, the time taken to deploy and remove an ART and the time to set and collect a BT was recorded to enable comparison of the time taken to use both methods.

\subsection{Data analysis}

The trapping data were used to calculate a catch per unit effort (CPUE) metric that enabled comparison of catch data over time and between trapping method. For each method, this was determined as the total number of crayfish captured in all traps per sampling occasion divided by the number of traps used. Correspondingly, for each sampling occasion, this provided a single CPUE value for the BTs and three CPUE values for ARTs (one for the 24-hour soak that was directly comparable to the BT data, one for the 6-day soak and a weekly total CPUE value (24-hour soak + 6-day soak)). The latter was calculated as it was considered that the two site visits to set and empty the BTs were commensurate with the effort required to empty the ARTs on days 1 and 6.

Testing whether sex ratios of captured crayfish differed from 1M:1F used Chi-square (goodness of fit). To compare CPUE between BTs and ARTs, two methods were used. The first method considered the data as paired, and thus tested mean CPUE data for BTs versus ARTs when they had been used in the same 24 hour sampling occasion. This was initially tested using a paired $t$-test, with mean CPUE from BT then plotted against ART and tested using linear regression, where the regression coefficient $(b)$ tested the null hypothesis that CPUE was equal between the methods on each trapping occasion. The null hypothesis was rejected when $b$ was significantly different to 1.0 and vice-versa, based on its $95 \%$ confidence limits (McDonald, 2014). The second method tested the effects of a range of abiotic and catch variables on the CPUE data within generalized linear models (GLM; family: linear). The initial model tested differences in CPUE only between BTs and ARTs when used for 24 hour periods. In the model, the dependent variable was CPUE per sampling occasion, the independent variable was 'trapping method', and the initial covariates entered into models were water temperature $\left({ }^{\circ} \mathrm{C}\right)$, flow $\left(\mathrm{m}^{3} \cdot \mathrm{s}^{-1}\right.$ ) (both taken as their value at 0900 on the day of trapping) and their interaction, plus total cumulative catch prior to each trapping day and sampling year. Temperature was included as a covariate due to its potential influence on crayfish activity levels and trapping success (Hein et al., 2007). As flow rarely affects the movement of crayfish (Bubb et al., 2004), it was included as a covariate to account for how elevated flows impacted trap performance. The models were run iteratively, with removal of non-significant covariates and comparisons of AIC to determine the parsimonious model, where the best fitting model was determined by the lowest AIC value. The outputs of the final model were estimated marginal means of CPUE ( $\pm 95 \%$ confidence limits) and the significance of their differences according to linearly independent pairwise comparisons (with Bonferroni adjustment for multiple comparisons). A second GLM was then used to test differences between the CPUE of BTs and ARTs, with the latter using data for the periods $24 \mathrm{~h}, 6$ days and 7 days, where for the 6 and 7 day data, CPUE represented the mean number of crayfish captured per trap in that period, rather than per day.

Crayfish size (as CL) was then tested for differences between trap type using a GLM; where CL was the dependent variable, trap type was the independent variable, and temperature, flow, year and cumulative catch were initial co-variates, with the same process used as described for CPUE. To compare the time taken to deploy and remove the BTs and ARTs from the river, the individual time data were compared via means and $95 \%$ confidence limits and then tested for the significance of their differences using ANOVA.

All statistics were completed using SPSS v.23.0 (IBM, 2017). Where error is presented around the mean, it represents $95 \%$ confidence limits unless otherwise stated.

\section{Results}

\subsection{Total catches and catch per unit effort (CPUE)}

A total of 5,897 crayfish were captured across the sampling years (Fig. 2A), with $87 \%$ of all crayfish captured in ARTs (Tab. 1). The cumulative catch of crayfish increased at a linear rate, but with overall mean CPUE declining by $25 \%$ across the entire period (Fig. 2B, C).

Comparison of the paired CPUE data revealed that the $24 \mathrm{~h}$ CPUE of ARTs was significantly higher than BTs (mean CPUE $0.47 \pm 0.07$ vs. $0.22 \pm 0.08 \mathrm{n} \cdot \mathrm{d}^{-1} ; t=-4.91, P<0.01$; Fig. 3 ). Linear regression also revealed their relationship deviated significantly from 1:1, rejecting the null hypothesis that CPUE would be similar between the trapping methods on specific trapping days $\left(R^{2}=0.05 ; F_{1,27}=1.54, P=0.23 ; 95 \%\right.$ confidence interval of $b=-0.07$ to 0.30 ) (Fig. 3). In GLMs testing differences in CPUE (as independent data) between BTs and ARTs over $24 \mathrm{~h}$, the non-significant covariates of water temperature $(P=0.92)$, the interaction of temperature and flow $(P=0.62)$ and cumulative catch $(P=0.47)$ were removed during model development. In the final model (AIC: -31.87 ), the only significant predictor of CPUE was the covariate of flow $(P<0.01)$, with the effect of trapping method and year both non-significant ( $P=0.97,0.15$ respectively). Mean CPUE was thus not significantly different between the two methods when the data were assessed as independent variables across the entire trapping period (BT: $0.26 \pm 0.05$, ART: $0.27 \pm 0.06$ $\mathrm{n} \cdot \mathrm{d}^{-1}$; Wald $\left.\chi^{2}=0.01, P=0.97\right)$. The best fitting GLM comparing CPUE from all methods and trapping periods involved all the entered covariates $(\mathrm{AIC}=-34.31$; GLM: Wald $\left.\chi^{2}=283.84, P<0.01\right)$, and with the exception of temperature $(P=0.13)$, the effects of all covariates were significant (flow, year, cumulative catch, $P<0.01$ in all cases). Mean CPUE values were again not significantly different between the trap types over $24 \mathrm{~h}(P=1.0)$, but were significantly different between these data and the ARTs fished 
Table 1. Summary of the total catch data by sex and life-stage. M: male; F: female; J: juveniles ( $<13 \mathrm{~mm})$; S: small ( $<20 \mathrm{~mm})$; M: medium $(21-$ $39 \mathrm{~mm})$; L: large ( $\geq 40 \mathrm{~mm})$; BF: berried female.

\begin{tabular}{lllllllll}
\hline Trap & $\mathrm{n}$ & $\mathrm{M}$ & $\mathrm{F}$ & $\mathrm{J}$ & $\mathrm{S}$ & $\mathrm{M}$ & $\mathrm{L}$ & $\mathrm{BF}$ \\
\hline ART & 5131 & 2344 & 2376 & 61 & 206 & 3887 & 1038 \\
BT & 766 & 457 & 305 & 1 & 1 & 183 & 579 & 5 \\
\hline
\end{tabular}
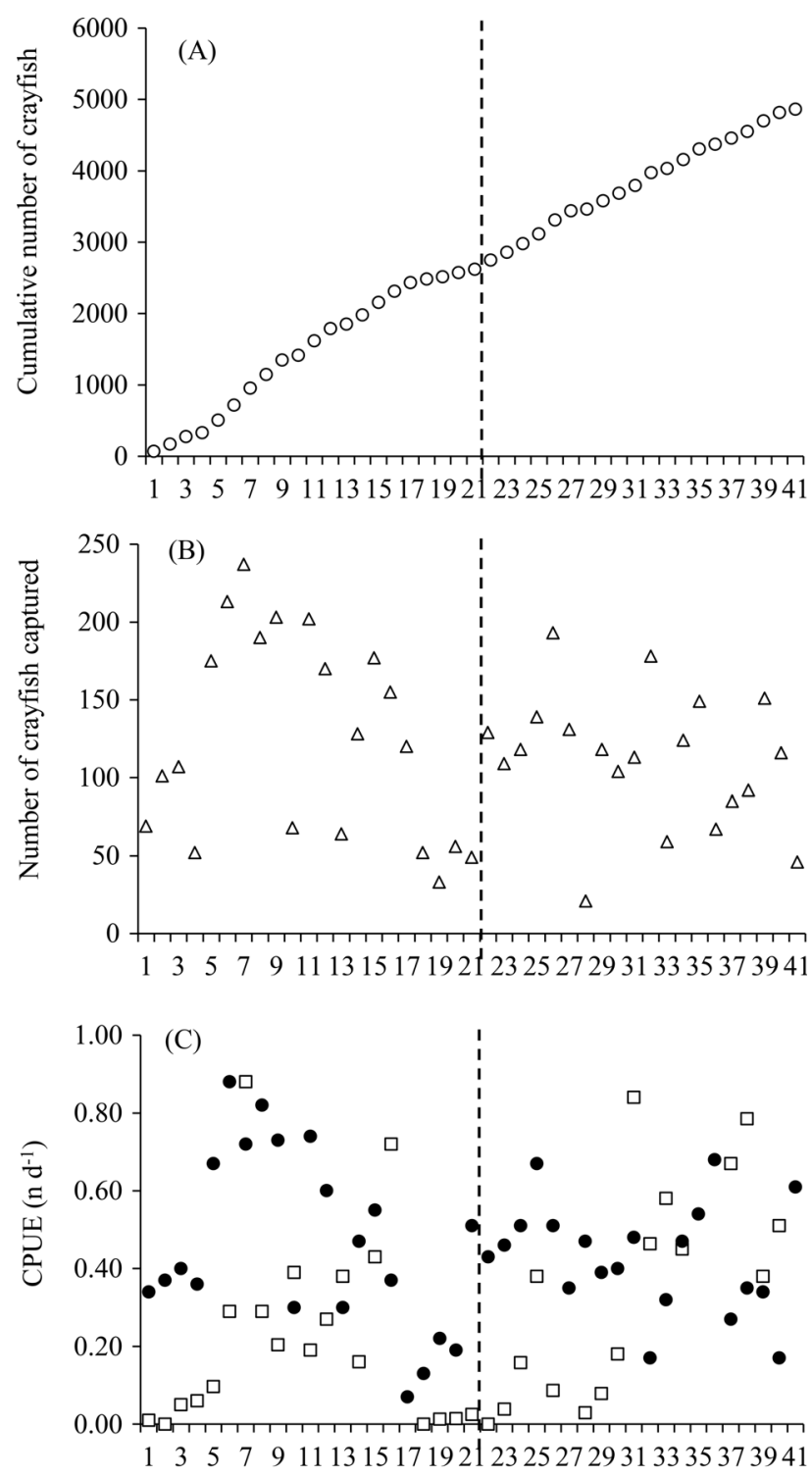

Trapping week

Fig. 2. (A) Cumulative number of crayfish removed from the site by both trapping methods; (B) Total number of crayfish captured during each trapping week; and (C) Catch per unit effort of crayfish by trapping week (artificial refuge traps: filled circles; baited traps open squares). In all cases, the vertical dashed line marks the split between 2015 and 2016 trapping years.

for 6 days $(0.69 \pm 0.07$ crayfish per trap over 6 days; $P<0.01$ in both cases $)$ and 7 days $(0.96 \pm 0.07$ crayfish per trap over 7 days; $P<0.01$ in both cases).

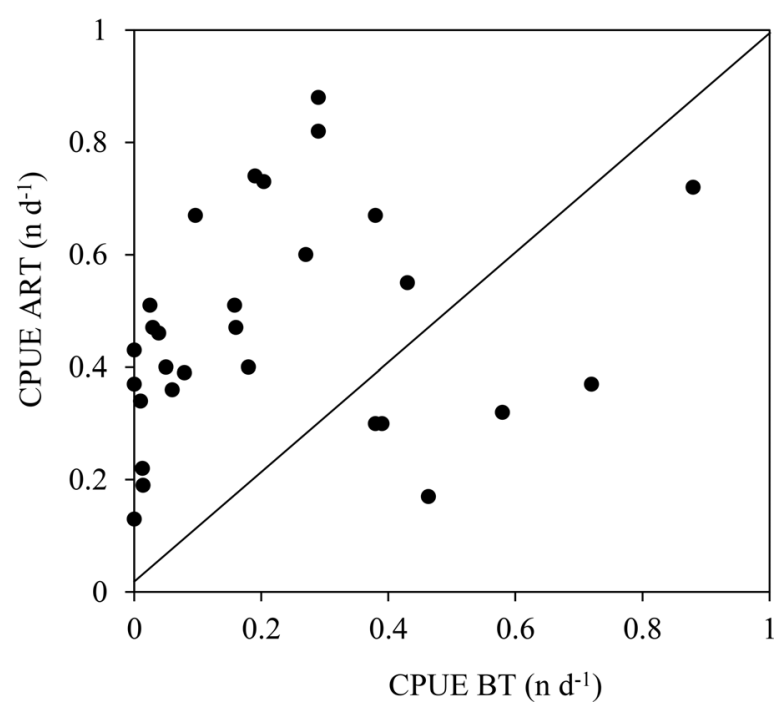

Fig. 3. Catch per unit effort of baited traps versus artificial refuge traps on the same 24 hour soak $(n=29)$; the $45^{\circ}$ line represents the 1:1 relationship in the CPUE of the two trapping methods.

\subsection{Catch composition by trapping method}

Comparison of the catch structure of the trapping methods revealed that the sex ratio of mature crayfish was significantly male biased in the BTs $\left(1.49 \mathrm{M}: 1 \mathrm{~F} ; \chi^{2}=28.60 ; P<0.01\right)$. In ARTs, of 4720 sexed crayfish captured (Tab. 1), the sex ratio was $0.99 \mathrm{M}: 1 \mathrm{~F}$, with this not significantly different to $1: 1\left(\chi^{2}=0.22\right.$; $P=0.64)$. Only one small crayfish was captured in the BTs versus 206 in ARTs (Tab. 1). ARTs also captured the majority of berried females $(95.4 \%)$ and moulting individuals $(89.4 \%)$.

The size ranges of crayfish captured across the trapping methods were similar (ARTs 4 to $62 \mathrm{~mm}$; BTs 11 to $64 \mathrm{~mm}$ ). However, the length distribution within these ranges differed considerably between the trap types, with a general pattern of ARTs capturing smaller sized individuals (Tab. 1; Fig. 4). The best fitting model testing length (as CL) between methods included all of the covariates being entered into the model except year $(P=0.61)$, with this final model being significant (AIC: -28.91 ; GLM: Wald $\chi^{2}=1141, P<0.01$ ). Mean CL of crayfish captured in ARTs was significantly smaller $(33.6 \pm 0.20 \mathrm{~mm})$ than BTs $(43.2 \pm 0.55 \mathrm{~mm})$. In this model, the covariates of temperature and cumulative catch were significant $(P<0.01)$, but flow was not $(P=0.07)$.

\subsection{Time taken for trap deployment/collection}

The mean time taken to bait and deploy then empty and store an individual BT was $87.3 \pm 10.4 \mathrm{~s}$ versus $33.2 \pm 16.4 \mathrm{~s}$ to 


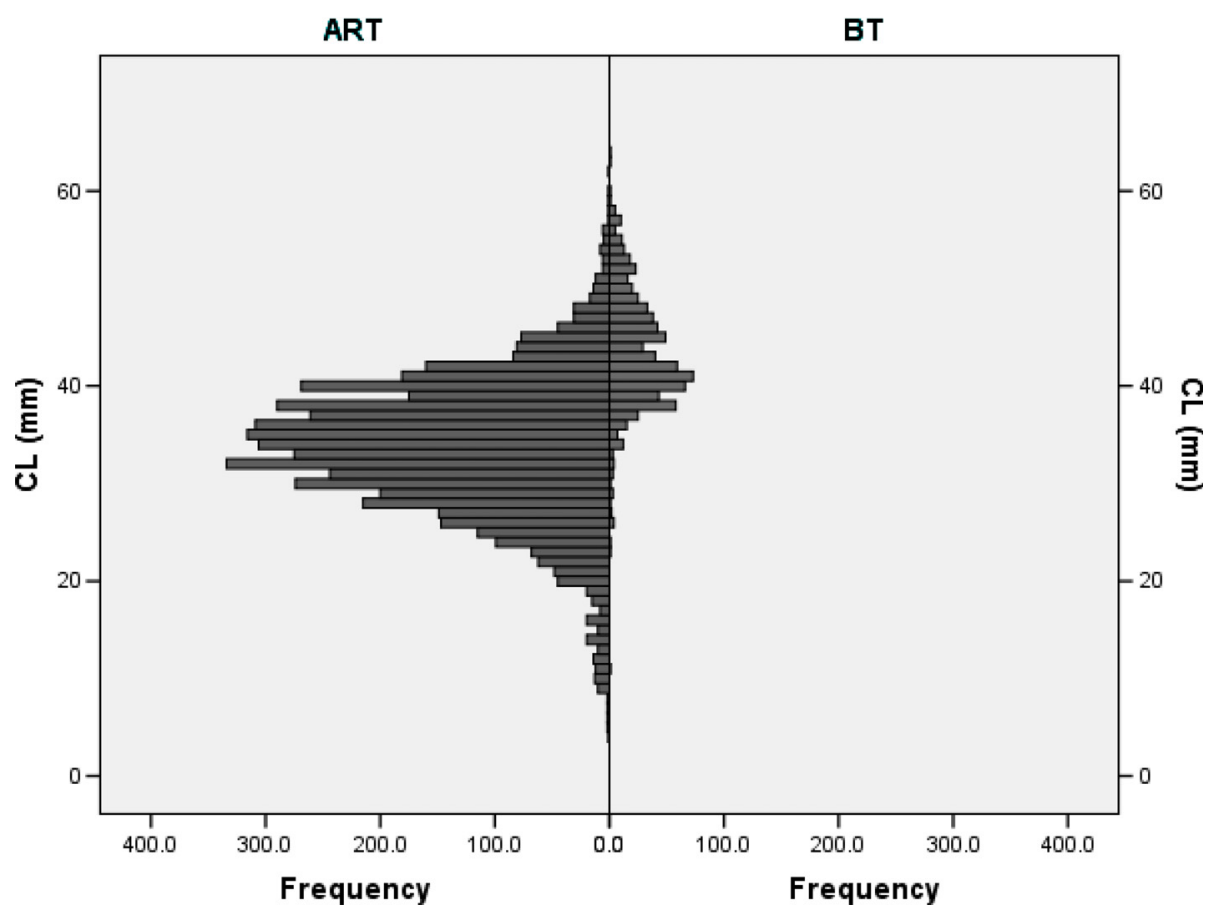

Fig. 4. Numbers of crayfish per size class (as their size frequency distribution) of the total catch of baited traps versus artificial refuge traps.

empty and reset the ART, with this difference significant $\left(F_{1,226}=965.01, P<0.01\right)$. Note these values exclude the time taken to purchase bait, remove it from and replace it to a storage facility after use.

\section{Discussion}

The trapping of crayfish over this two-year period in the study reach revealed that ARTs had a significantly higher CPUE than BTs when directly compared over 24-hour periods (i.e. as paired data). The ability to leave ARTs to fish for sixday periods, something not possible with BTs, then resulted in them capturing significantly higher numbers of crayfish than both trapping methods fished for 24 hours. In addition to their lower CPUE, BTs generally require more regular management in relation to emptying and re-baiting compared to more passive forms of capture (Gherardi et al., 2011). As ARTs work in a different manner to BTs via their provision of an alternative and heterogeneous habitat for crayfish then it means it can be desirable for them to be left in situ for extended periods to enable higher rates of colonisation. When the two trapping methods were compared across the two year sampling period (i.e. not as paired data) then although these indicated the overall differences in CPUE were not significantly different, they did indicate that increased flow rates inhibited the catch efficiency of both methods.

The study reach was located on an upland spate river of relatively low productivity and the crayfish population was estimated as being as of medium abundance (N. Green, pers. obs.). Thus, leaving the ARTs in situ for six-day periods did not result in the artificial refuges on the traps being saturated with crayfish, thus shortening the time between emptying would not necessarily have increased capture rates. In addition, as crayfish use the ARTs as habitat and are not enclosed within them, the longer the saturation period also does not necessarily mean the greater the catch. If these traps are subsequently applied to populations of higher abundance then work should initially determine if the refuges are rapidly colonised and, if so, then reducing the time between setting and emptying should increase catches. Although work is underway currently to determine the optimum soak length for ARTs on the study site, on a wider scale this is likely to be influenced by contextdependent factors such as population density and habitat quality (e.g. availability of alternative natural refuges).

A further option to increase catch sizes per ART would be to increase the number of refuges (tubes) per trap. As signal crayfish tend to be aggressive and cannibalistic, including antagonistic interactions between individuals that can result in displacement (Graham and Herberholz, 2009; Hudina et al., 2016), it had been assumed that each tube would only be able to capture an individual, thereby limiting catch size to the number of tubes per trap. This was not the case, however, with multiple crayfish sometimes captured in a single tube. This was interpreted as being due to ARTs capturing smaller individuals than BTs, with higher proportions of females that tend to be less aggressive than large bodied males (Berry and Breithaupt, 2010) and thus were more likely to co-habit tubes.

The size distribution of crayfish captured in the ARTs differed to the BTs, with a general pattern of catches comprising individuals of smaller carapace length, with this consistent with the hypothesis. Moreover, the most frequently captured size class in ARTs was 21 to $39 \mathrm{~mm} \mathrm{CL}$, with individuals of below $30 \mathrm{~mm}$ often dominating population size structure (Houghton et al., 2017), whereas BTs predominantly captured individuals above $40 \mathrm{~mm}$ CL. This 'medium' size range in the ARTs generally covered the 'sub-adult' and 'subordinate adult' components of the population and it is 
these individuals that tend to show the density-dependent compensatory responses (e.g. increased growth rates and fecundity) to the removal of larger adults by BTs (Skurdal and Qvenild, 1986; Moorhouse and McDonald, 2011). Therefore, the application of ARTs with BTs potentially reduce the effects of these compensatory responses and thus their combined use could increase the effectiveness of invasive crayfish control attempts when trapping is employed. It should be noted, however, that although ARTs captured crayfish as small as $4 \mathrm{~mm} \mathrm{CL}$, small crayfish (i.e. $<20 \mathrm{~mm} \mathrm{CL}$ ) were still poorly represented in catches and thus despite their ability to capture a far greater proportion of smaller crayfish than BTs, including an abundance of animals between 21 and $30 \mathrm{~mm} \mathrm{CL}$, ARTs are also unable to target all life stages of an invasive crayfish population equally.

There were higher proportions of females captured in the ARTs than the BTs; where catches in BTs were significantly male dominated, they were of approximately equal sex ratio in ARTs, although the hypothesis had predicted female dominated catches. Although female crayfish are believed to be less active than males and thus are seen as being less vulnerable to trapping (Gherardi et al., 2011), their frequent capture in the ARTs suggests that they can be as vulnerable as males to some trapping methods. Indeed, the removal of large numbers of females, especially sub-adults, might increase the effectiveness of a trapping programme by removing individuals prior to their first spawning event (Stebbing et al., 2012). In addition, the large numbers of berried females captured and removed could reduce juvenile recruitment substantially. Although not investigated in detail here, the ability of ARTs to capture both moulting animals and berried/ brooding females should also enable further study of their natural behaviours in the wild which could provide insights into traits, such as growth rates and productivity, that could inform and enhance an invasion control programme or, in the case of native crayfish, assist in the development of a conservation strategy (Rogowski et al., 2013).

It has been postulated that traps that are able to remove large numbers of multiple life stages of crayfish are likely to be more effective at eradication or long-term suppression of a population than those that capture only specific size or length classes (Dana et al., 2010; Stebbing et al., 2012). Studies on the management of invasive crayfish also tend to stress the importance of long-term control efforts that aim to not only remove substantial proportions of the population but also prevent their rapid population recovery via compensatory responses (e.g. Gherardi et al., 2011; Moorhouse and McDonald, 2011). Consequently, long-term control methods need to consider the cost of the methods employed in order to ensure the maximum cost-benefit of the approach (Peay, 2004; Simberloff, 2009). The results reported here suggested that ARTs were more cost effective and precise than BTs in terms of the time per individual crayfish removed and thus long-term crayfish control efforts could have higher feasibility when these are used. However, since BTs capture larger size classes then the most effective trapping technique is likely to be their combined use, ensuring a wider range of life-stages would be removed on each trapping occasion.

It is recommended that future studies also include trials on lentic systems and utilise alternative designs that could potentially capture larger numbers of crayfish and target different size classes, especially young-of-year. For example, tube sizes could be varied to target different size classes, and tubes could be stacked to form bundles. Studies could also be conducted on the efficacy of control attempts using ARTs alone, with investigation of the optimal time of year to catch different sexes and size classes and the optimum length of soak in relation to the abundance of the target population of crayfish.

In summary, the results of this trapping programme on a lotic invasive crayfish population revealed that the application of ARTs provided substantial benefits to population control and the capture of a more representative length range and sex distribution compared with BTs. They also had a higher CPUE than BTs in the same 24 hour period and over longer trapping periods, enabling the capture of substantially higher numbers of crayfish with lower labour input. Thus, ARTs represent a more cost-effective methodology than BTs. Correspondingly, it is recommended that when invasive crayfish populations are being controlled via trapping, a combination of trap types be utilised to ensure that all life-stages are vulnerable to capture and that trapping efficiency is maintained at low population abundance.

Acknowledgements. The authors would like to thank project partners Exmoor National Park Authority, Natural England, Environment Agency (Devon Team), River Exe Tributaries Association, River Barle Fishing Club and South West Water for their support both financial and practical. Thanks are also due to the project volunteers who generously donated their time and enthusiasm to the trapping study.

\section{References}

Andreou D, Feist SW, Stone D, Bateman K, Gozlan RE. 2011. First occurrence and associated pathology of Sphaerothecum destruens in cyprinids. Dis Aquat Org 95: 145-151.

Arim M, Abades SA, Neill PE, Lima M, Marquet PA. 2006. Spread dynamics of invasive species. Proc Nat Acad Sci USA 103: 374 378.

Bechler D, Hightower P, Rousey J, Smith M. 2014. The use of nest traps to study behaviour, population structure and life history of Procambarus spiculifer. Freshwater Crayfish 20: 7-16.

Berry F, Breithaupt T. 2010. To signal or not to signal? Chemical communication by urine-borne signals mirrors sexual conflict in crayfish. BMC Biology 8: 25.

Bomford M, O'Brien P. 1995. Eradication or control for inverteybrate pests? Wildl Soc Bull 23: 249-255.

Bubb DH, Thom TJ, Lucas MC. 2004. Movement and dispersal of the invasive signal crayfish Pacifastacus leniusculus in upland rivers. Freshw Biol 49: 357-368.

Byrne C, Lynch J, Bracken J. 1999. A sampling strategy for stream populations of white-clawed crayfish, Austropotamobius pallipes. Biology and Environment. Proc Roy Irish Acad 99B: 89-94.

Capinha C, Leung B, Anastácio P. 2011. Predicting worldwide invasiveness for four major problematic decapods: an evaluation of using different calibration sets. Ecography 34: 448-459.

CEH. 2017. 45011: River Barle at Brushwood. http://nrfa.ceh.ac.uk/ data/station/meanflow/45011. (Last accessed 04/08/2017).

Dana ED, López-Santiago J, García-de-Loma J, García-Ocaña DM, Gámez V, Ortega F. 2010. Long-term management of the invasive Pacifastacus leniusculus (Dana, 1852) in a small mountain stream. Aquat Invasions 5: 317. 
Engdahl F, Fjalling A, Sandstrom A, Bohman P, Edsman L. 2013. A trial of natural habitat enclosure traps as a sampling tool for juvenile crayfish. Freshwater Crayfish 19: 137-144.

Freeman M, Turnbull J, Yeomans W, Bean C. 2009. Prospects for management strategies of invasive crayfish with an emphasis on biological control. Aquat Conserv 20: 211-233.

Freeman MA, Turnbull JF, Yeomans WE, Bean CW. 2010. Prospects for management strategies of invasive crayfish populations with an emphasis on biological control. Aquat Conserv 20: 211-223.

Gherardi F, Aquiloni L, Diéguez-Uribeondo J, Tricarico E. 2011. Managing invasive crayfish: is there a hope? Aquat Sci 73: 185-200.

Graham ME, Herberholz J. 2009. Stability of dominance relationships in crayfish depends on social context. Anim Behav 77: 195-199.

Green N. 2015. Guidance on the use of artificial refugia for freshwater crayfish species. Bovey Tracey, Devon: Nicky Green Associates.

Guan RZ, Wiles PR. 1997. Ecological impact of introduced crayfish on benthic fishes in a British lowland river. Conserv Biol 11: 641647.

Harrison ML, Hoover TM, Richardson JS. 2006. Agonistic behaviours and movement in the signal crayfish, Pacifastacus leniusculus: can dominance interactions influence crayfish sizeclass distributions in streams? Can J Zool 84: 1495-1504.

Hein C, Vander Zanden J, Magnuson J. 2007. Intensive trapping and fish predation cause massive population decline of an invasive crayfish. Freshwater Biol 52: 1134-1146.

Holdich DM, Reeve IS. 1991. Distribution of freshwater crayfish in the British Isles, with particular reference to crayfish plague, alien introductions and water quality. Aquat Conserv 1: 139-158.

Holdich D, Reynolds J, Souty-Grousset C, Sibley P. 2009. A review of the ever increasing threat to European crayfish from nonindigenous crayfish species. Know Man Aquat Ecosys 11: 394-395

Holdich DM, James J, Jackson C, Peay S. 2014. The North American signal crayfish, with particular reference to its success as an invasive species in Great Britain. Eth Ecol Evol 26: 232-262.

Houghton RJ, Wood C, Lambin X. 2017. Size-mediated, densitydependent cannibalism in the signal crayfish Pacifastacus leniusculus (Dana, 1852) (decapoda, astacidea), an invasive crayfish in Britain. Crustaceana 90: 417-435.

Hudina S, Zganec K, Hock K. 2015. Differences in aggressive behaviour along the expanding range of an invasive crayfish: an important component of invasion dynamics. Biol Invasions 17: 3101-3112.

Hudina S, Hock K, Radović A, et al. 2016. Species-specific differences in dynamics of agonistic interactions may contribute to the competitive advantage of the invasive signal crayfish (Pacifastacus leniusculus) over the native narrow-clawed crayfish (Astacus leptodactylus). Mar Freshw Behav Physiol 49: 147-157.

IBM. 2015. SPSS Statistics 23. https://www.ibm.com/analytics/us/en/ technology/spss/.

IBM. 2017. IBM SPSS Statistics V23.0 documentation. https://www. ibm.com/support/knowledgecenter/en/SSLVMB_23.0.0/spss/pro duct_landing.html.

Jackson MC, Jones T, Milligan M, et al. 2014. Niche differentiation among invasive crayfish and their impacts on ecosystem structure and functioning. Freshwater Biol 59: 1123-1135.

Jackson M, Grey J, Miller K, Britton JR, Donohue I. 2016. Dietary niche constriction when invaders meet natives: evidence from freshwater decapods. J Anim Ecol 85: 1098-1107.

Kats LB, Bucciarelli G, Vandergon TL, et al. 2013. Effects of natural flooding and manual trapping on the facilitation of invasive crayfish-native amphibian coexistence in a semi-arid perennial stream. J Arid Environ 98: 109-112.
Kozak P, Policar T. 2002. Practical elimination of signal crayfish $P$. leniusculus from a pond. In Holditch D, Sibley P. eds. Management and Conservation of Crayfish. Proceedings of a conference held on $7^{\text {th }}$ November 2002. Bristol: Environment Agency, pp. 200-209.

Kusab I, Quinn J. 2009. Use of a traditional Maori harvesting method, the tau koura, for monitoring koura (freshwater crayfish, Paranephrops planifrons) in Lake Rotoiti, North Island, New Zealand. New Zeal J Mar Freshw Res 43: 713-722.

Larson E, Olden J. 2016. Field sampling techniques for crayfish. In Stebbing P, Longshaw M. eds. Biology and Ecology of crayfish. London: CRC Press, pp. 287-324.

Lodge DM, Deines A, Gherardi F, et al. 2012. Global introductions of crayfishes: evaluating the impact of species invasions on ecosystem services. Ann Rev Ecol Evol Sys 43: 449-472.

Mathers KL, Chadd RP, Dunbar MJ, et al. 2016. The long-term effects of invasive signal crayfish (Pacifastacus leniusculus) on instream macroinvertebrate communities. Sci Total Enviro 556: 207-218.

McDonald, JH. 2014. Handbook of Biological Statistics, 3rd ed. Baltimore, Maryland: Sparky House Publishing.

Moorhouse T, McDonald D. 2011. The effect of removal by trapping on body condition in populations of signal crayfish. Biol Conserv 144: $1826-1831$.

Natural England. 2017. River Barle SSSI. https://designatedsites. naturalengland.org.uk/SiteDetail.aspx SiteCode $=$ S2000143\&Site Name $=$ barle \& countyCode $=\&$ responsiblePerson. $\quad$ (Last accessed 13/01/2018)

Parkyn S, DiStefano R, Imhoff I. 2011. Comparison of constructed microhabitat and baited traps in Table Rock Reservoir, Missouri USA. Freshwater Crayfish 18: 69-74.

Peay S. 2004. A cost-led evaluation of survey methods and monitoring for white-clawed crayfish - lessons from the UK. Bulletin Français de la Pêche et de la Pisciculture 372-373: 335-352.

Rice SP, Johnson MF, Extence C, Reeds J, Longstaff H. 2014. Diel patterns of suspended sediment flux and the zoogeomorphic agency of invasive crayfish. Patrones diarios del flujo de sedimento en suspensión y el efecto zoogeomórfico del cangrejo de río invasor 40: 7.

Rogowski DL, Sitko S, Bonar SA. 2013. Optimising control of invasive crayfish using life-history information. Freshw Biol 58: 1279-1291.

Scott B. 2012. The efficacy of artificial refuge traps for the monitoring of the invasive signal crayfish Pacifastacus leniusculus (MSc thesis). School of Civil Engineering and the Environment, University of Southampton.

Simberloff D. 2009. We can eliminate invasions or live with them. Successful management projects. Biol Invasions 11: 149-157.

Skurdal J, Qvenild T. 1986. Growth, maturity, and fecundity of Astacus astacus in lake Steinsfjorden, S.E. Norway. Freshwater Crayfish 6: 182-186.

Smith P, Wright R. 2000. A preliminary consideration of some aspects relating to the population dynamics of signal crayfish $(P$. leniusculus) with a view to assessing the utility of trapping as a removal method. In Rogers D, Brickland J. eds. Proceedings of the Crayfish Conference held on 26th/27th April 2000. Leeds, pp. 8793.

Stebbing PD, Longshaw M, Taylor N, et al. 2012. Review of methods for the control of invasive crayfish in Great Britain, final report C5471. Weymouth, UK: CEFAS.

Stebbing P, Longshaw M, Scott A. 2014. Review of methods for the management of non-indigenous crayfish, with particular reference to Great Britain. Eth Ecol Evol 26: 204-231. 
N. Green et al.: Knowl. Manag. Aquat. Ecosyst. 2018, 419, 15

Trappy. 2017. Crayfish Traps. http://trappy.com/eng/products/cray fishtraps/. (Last accessed 04/08/2017).

Twardochleb LA, Olden JD, Larson E. 2013. A global meta-analysis of the ecological impacts of non-native crayfish. Freshw Sci 32: $1367-1382$.
Walter K. 2012. An evaluation of whether artificial refuge traps or baited traps are the most effective method for trapping Whiteclawed crayfish Austropotamobius pallipes in the Creedy Yeo River, Devon. The Plymouth Student Scientist 5: 443-485.

Cite this article as: Green N, Bentley M, Stebbing P, Andreou D, Britton R. 2018. Trapping for invasive crayfish: comparisons of efficacy and selectivity of baited traps versus novel artificial refuge traps. Knowl. Manag. Aquat. Ecosyst., 419, 15. 